\title{
COMPARISON BETWEEN CONCENTRATED BONE MARROW ASPIRATE AND CORTICOID IN GLUTEAL TENDINOPATHY
}

\section{COMPARAÇÃO ENTRE O ASPIRADO DE MEDULA ÓSSEA CONCENTRADO E O CORTICÓIDE NA TENDINOPATIA GIUUTEA}

\author{
Davi araújo Veiga Rosário ${ }^{1}$ (1), Thiago batista Faleiro ${ }^{2}$ (i), Bruno adelmo ferreira Mendes Franco ${ }^{2}$ (1), \\ GILDÁSIO DE CERQUEIRA DALTRO² (D), REINALDO MARCHETTO ${ }^{1}$ (1)
}

1. Universidade Estadual Paulista, Araraquara, SP, Brazil.

2. Universidade Federal da Bahia, Salvador, BA, Brazil.

\section{ABSTRACT}

Objective: To compare bone marrow aspirate concentrate (BMAC) with the standard treatment for gluteal tendinopathies. Methods: 48 patients diagnosed with gluteal tendinopathy at a university hospital were selected by a randomized clinical trial and divided into two groups: (G1) bone marrow aspirate concentrate and (G2) corticosteroid injections. Results: 40 of the 48 selected patients were monitored for six months and both groups showed better scores. Visual analog scale (VAS) scores and Lequesne index were statistically significant higher in patients submitted to BMAC treatment when compared to standard treatment. Both groups improved their quality of life, without statistically significant difference. Conclusion: BMAC constitutes an alternative to gluteal tendinopathy standard treatment, proving to be a safe technique with promising results when combined with multidisciplinary team behavioral therapy. Level of Evidence II, Randomized Clinical Trial.

Keywords: Tendinopathy. Bone Marrow Cells. Hip Joint. Adrenal Cortex Hormones.

\section{RESUMO}

Objetivo: Estudo comparativo entre tratamento com corticóide e aspirado de medula óssea concentrado (BMAC) para o tratamento de tendinopatias glúteas. Métodos: O ensaio clínico randomizado selecionou pacientes diagnosticados com tendinopatia glútea e os dividiu em dois grupos: (G1) aspirado de medula óssea concentrada e (G2) injeção de corticosteróide. Resultados: Foram selecionados 48 pacientes, dos quais 40 foram monitorados por 6 meses, com melhora nos escores nos dois grupos. Os pacientes que foram submetidos ao tratamento com BMAC tiveram uma melhora estatisticamente significativa nos escores de EVA e nos escores de Lequesne em comparação ao tratamento padrão. Houve uma melhora na avaliação da qualidade de vida em ambos os grupos, sem diferença estatisticamente significativa. Conclusão: O aspirado de medula óssea concentrada surge como uma alternativa ao tratamento padrão da tendinopatia glútea, provando ser uma técnica segura e com resultados promissores quando combinada à terapia comportamental de equipe multidisciplinar. Nível de Evidência II, O ensaio clínico randomizado.

Descritores: Tendinopatia. Células da Medula Óssea. Articulação do Quadril. Corticosteroides.

Citation: Rosário DAV, Faleiro TB, Franco BAFM, Daltro GC, Marchetto R. Comparison between concentrated bone marrow aspirate and corticoid in gluteal tendinopathy. Acta Ortop Bras. [online]. 2021;29(1):26-9. Available from URL: http://www.scielo.br/aob.

\section{INTRODUCTION}

Tendinopathy is a tendon disorder characterized by activity-related pain, local edema, focal tenderness on palpation, and decreased strength in the affected area. ${ }^{1}$ Several scientific studies address adult gluteal tendinopathy due to its prevalence. Also known as "hip bursitis," gluteal tendinopathy is often referred to as greater trochanteric pain syndrome (GTPS). GTPS includes several peritrochanteric space disorders of the hip, such as tendinopathy of the gluteus medius and gluteus minimus muscles, snapping hip syndrome, and trochanteric bursitis. ${ }^{2}$
Pathologies affecting the periarticular hip space should be included within differential diagnosis. Traumatic injuries in the direct portion of the rectus femoris muscle incur anterior hip pain and knee extensor strength deficit. Ischiofemoral impingement syndrome is a condition that narrows the proximal femur-ischium space of patients with reduced horizontal offset, causing groin and gluteal pain due to entrapment of the quadratus femoris muscle and surrounding structures. Athletic pubalgia is a syndrome that affects young patients who practice sports regularly, causing groin pain due to a chronic inflammatory process in the pubic symphysis

All authors declare no potential conflict of interest related to this article.

\footnotetext{
The study was conducted at the Complexo Hospitalar Professor Edgard Santos of the Universidade Federal da Bahia, and it is part of the main author's doctoral program at the Universidade Estadual Paulista.
}

Correspondence: Davi Araújo Veiga Rosário. Rua Oito de Dezembro, 254, ap. 801, Salvador, BA, Brazil, 40150000. daviveiga@hotmail.com 
associated with adductor tendinopathy. ${ }^{3}$ Clinical studies show a high prevalence of GTPS, peaking from the sixth decade of life. A cohort study conducted with patients aged between 50 and 79 years found the prevalence of unilateral GTPS to be 15\% among women and $6.6 \%$ among men and bilateral GTPS to be $8.5 \%$ among women and $1.9 \%$ among men. ${ }^{4}$

The standard treatment for gluteal tendinopathies consists of an extensive rehabilitation protocol with the use of physical agents (ultrasound, electrical stimulation, and cryotherapy) to relieve pain. Kinesiotherapy is administered to reestablish the function of the muscle group by proper movement, postural realignment, and muscle stretching. ${ }^{5}$ For moments of more intense pain, routine analgesics and anti-inflammatories are prescribed. Rest must be proportional, and sports practices must be monitored throughout the recovery process. ${ }^{5}$

Corticosteroids local injection (an invasive method) is often administered to reduce local inflammation and decrease pain, consequently improving the affected hip functional condition. Surgical interventions are reserved for standard treatment-resistant cases and may vary from tendon debridement to tendon reinsertion/footprint. ${ }^{6}$

The challenge for the upcoming years is to change concepts regarding tissue regeneration in a feasible, clinically plausible, and economically viable manner. Surgical practices have shown an increasing interest in bone marrow aspirate concentrate (BMAC) applications and tissue engineering approaches for treating damaged or lost tissues resulting from sports or traumatic injuries ${ }^{7}$ due to several factors, including increased familiarity with bone marrow-derived mesenchymal stem cells. Recent techniques such as gene transfer, cell therapy, and application of growth factors show great capacity of becoming effective biological therapies, given that many studies have successfully introduced markers and therapeutic genes in ligaments and tendons. ${ }^{8}$

This study sought to compare the efficacy of BMAC with corticosteroid injection in the treatment of gluteal tendinopathies.

\section{MATERIALS AND METHODS}

Ethical aspects

This study was developed according to Resolution No. 466/12, which regulates research involving human beings. The research project was submitted to and approved by the Research Ethics Committee of Hospital Universitário Professor Edgard Santos. CAE: 72236317200000049 .

\section{Group of participants}

Our study sample comprised 48 patients of both sexes, aged between 18 and 73 years, with clinical and radiological diagnosis of gluteal tendinopathy. These patients' nuclear magnetic resonance (NMR) were analyzed and ultrasound was performed at the outpatient clinic. All patients agreed to participate in the study by signing the informed consent form. Physical therapy treatment protocol, lifestyle changing recommendations, and analgesic treatment were the same for all participants.

\section{Exclusion criteria}

Participants presenting infection at the surgical site or with comorbidities and contraindications for the surgical procedure were excluded.

\section{Monitoring plan}

Monitoring visits occurred before the surgical procedure and one, three, and six months after stem cell-based grafting or corticosteroid injection. To compare condition evolution, Visual Analogue Scale (VAS), and the Lequesne (functional score) and EuroQol-5D (quality of life score) questionnaires were administered to participants on the day of the procedure and during monitoring visits.

\section{Randomization}

Using a computer-based system, patients were randomized into two groups: bone marrow aspirate concentrate (G1) or corticosteroid treatment (G2).

\section{Procedures}

Stem cells were collected and injected in a surgical center, with the patient under sedation and analgesia and placed in supine position (standard for hip surgery). With the patient under spinal anesthesia and mild sedation, bone marrow aspirate was obtained by inserting a Jamshidi needle $5 \mathrm{~cm}$ deep toward the cancellous bone of the anterior iliac crest, so that its tip was located between the inner and outer tables. About $100 \mathrm{~mL}$ of bone marrow was aspirated using disposable $10-\mathrm{mL}$ syringes preloaded with anticoagulant. Syringes containing bone marrow aspirates were grouped in sterile surgical grade and their contents transferred to a blood collection bag. An automated and closed system was used to separate and concentrate the fraction of mononuclear cells obtained from bone marrow aspirate $\left(\right.$ Sepax $\left.{ }^{\circledR}\right)$.

Cell counting and viability assessment were performed using a small cells suspension at the procedure site. Live cells were sampled by anti-CD34 antibody staining and Propidium lodide incorporation.

\section{BMAC}

Using an ultrasound-guided standard $10-\mathrm{mL}$ syringe, $20 \mathrm{~mL}$ of the solution with BMAC was injected in the gluteal tendon footprint (Figure 1).

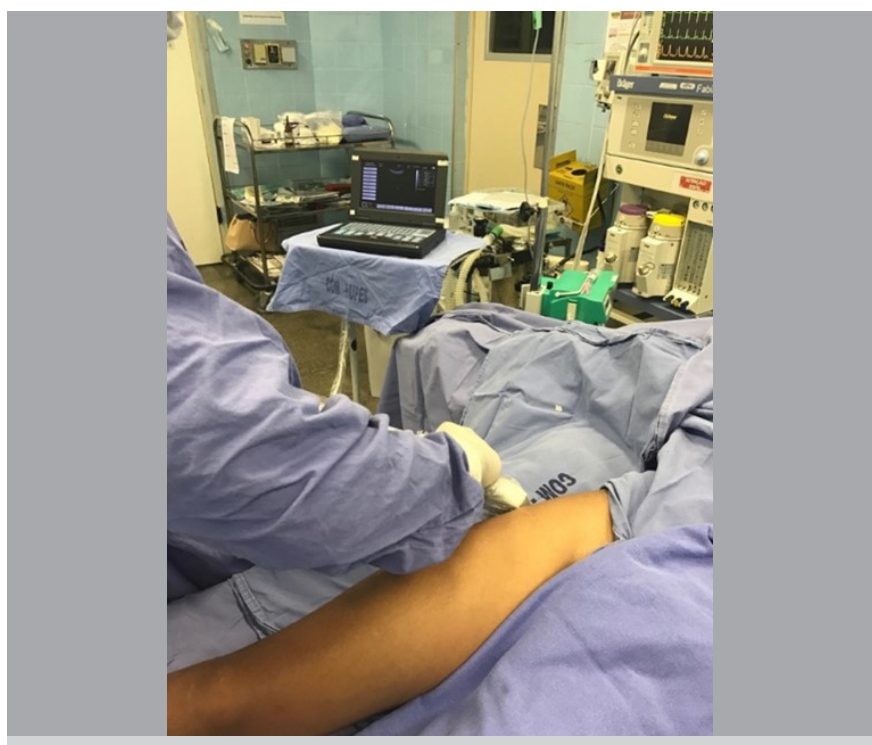

Figure 1. Ultrasound-guided BMAC therapy.

\section{Corticosteroid injection}

Corticosteroid injection was performed in an operating room at the outpatient clinic according to the Health Surveillance norms. After local anesthesia using $2 \%$ lidocaine without vasoconstrictor at $2 \mathrm{~mL}$, a solution containing $7 \mathrm{mg}$ of betamethasone associated with $4 \mathrm{~mL}$ of $2 \%$ lidocaine without vasoconstrictor was injected using a $0.7 \times 30 \mathrm{~mm}$ needle, guided by ultrasound.

\section{Data Analysis Plan}

Database creation, descriptive analysis, and analytical analysis were performed using the software Statistical Package for Social Sciences (SPSS), version 14.0 for Windows ${ }^{\circledR}$. Data normality was verified using Shapiro-Wilk test, descriptive statistics, and graphic analysis, and the results are presented in tables and graphs. Categorical variables are expressed in absolute and percentage values $-\mathrm{n}(\%)$; 
continuous variables with normal distribution are expressed as mean and standard deviation $( \pm S D)$ and those with asymmetrical distribution in median and interquartile range (IQR). Significance level was set at $5 \%$ for inferential analyses.

\section{RESULTS}

Eight of the 48 evaluated patients were lost to follow-up (16\%). Thus, 40 patients were monitored for six months and completed the rehabilitation protocol.

From the 40 participants, twenty (50\%) were men and twenty (50\%) women. The average age in the bone marrow aspirate concentrate (BMAC) group (G1) was 46.1 years old ( \pm 15.2 years old), and in the corticosteroid group (G2) 53.2 years old ( \pm 12 years old). Most participants (57.5\%) completed high school and only $12.5 \%$ of those currently studying got a leave of absence and were receiving the National Institute of Social Security (INSS) benefits. As for comorbidities, $47.5 \%$ of the sample presented arterial hypertension and $30 \%$ presented diabetes mellitus. Depression was highly prevalent among study participants (22.5\%) when compared to the overall population of the same age group (4.4\%), corroborating the results reported by other studies that demonstrate a strong association between depressive disorders and gluteal tendinopathy (Table 1).

Table 1. Comparison of sociodemographic and clinical characteristics.

\begin{tabular}{|c|c|c|c|}
\hline Variables & $\begin{array}{c}\text { BMAC Group } \\
(n=15)\end{array}$ & $\begin{array}{c}\text { Corticosteroid Group } \\
(n=25)\end{array}$ & p-value ${ }^{\star *}$ \\
\hline Age $($ Mean \pm SD) & $46,1 \pm 15,2$ & $53,2 \pm 12,0$ & 0,110 \\
\hline Sex & $n(\%)$ & $n(\%)$ & \\
\hline Male & $10(66,7)$ & $10(40,0)$ & \\
\hline Female & $05(33,3)$ & $15(60,0)$ & \\
\hline \multicolumn{4}{|l|}{ Education } \\
\hline Primary & $04(26,7)$ & $10(40,0)$ & \multirow{3}{*}{0,451} \\
\hline Secondary & $09(60,0)$ & $14(56,0)$ & \\
\hline Tertiary & $02(13,3)$ & $01(4,0)$ & \\
\hline INSS & $04(26,7)$ & $01(4,0)$ & 0,056 \\
\hline \multicolumn{4}{|l|}{ Comorbidities } \\
\hline Arterial hypertension & $05(33,3)$ & $14(56,0)$ & 0,165 \\
\hline Diabetes Mellitus & $02(13,3)$ & $10(40,0)$ & $0,152^{*}$ \\
\hline Depression & $05(33,3)$ & $04(16,0)$ & $0,255^{\star}$ \\
\hline Sickle Cell Anemia & $00(0,0)$ & $01(4,0)$ & $1,000^{*}$ \\
\hline Labyrinthitis & $00(0,0)$ & $01(4,0)$ & $1,000^{\star}$ \\
\hline Glaucoma & $00(0,0)$ & $01(4,0)$ & $1,000^{*}$ \\
\hline \multicolumn{4}{|l|}{ Sports Activity } \\
\hline Sedentary lifestyle & $02(13,3)$ & $20(80,0)$ & \multirow{6}{*}{$<0,001$} \\
\hline Pilates & $03(20,0)$ & $02(8,0)$ & \\
\hline Soccer & $05(33,3)$ & $01(4,0)$ & \\
\hline Water aerobics & $03(20,0)$ & $00(0,0)$ & \\
\hline Gym & $02(13,3)$ & $00(0,0)$ & \\
\hline Walking & $00(0,0)$ & $02(8,0)$ & \\
\hline
\end{tabular}

Most participants did not practice regular physical activity. At baseline, 55\% of the study sample lacked the habit of practicing regular and guided sports. Among those who did regular physical activity, soccer was the most prevalent (15\%). However, all patients reported complying with lifestyle changes recommendations, performing activities at least 3 times a week for 30 minutes. Guided activity entails a warm-up, physical exercise with cardiovascular stimulus, and post-workout stretching. Sex, age, education, INSS, and comorbidities were homogeneous between our study groups.

Comparing VAS scores obtained at baseline and at six-month follow-up, we verified pain to progressively reduce at about $67 \%$ in patients treated with BMAC (G1) and at about $34 \%$ in patients treated with corticosteroid injection (G2), with statistical significance $(p<0.001)$. At six-month follow-up, the median value was 2 in G1 and 4 in $G 2$, with statistical significance $(p<0.01)$.

The intragroup evaluation regarding the Lequesne questionnaire found $\mathrm{G} 1$ to show a 4-point reduction from baseline to six-month follow up, whereas this reduction was of 1.2 points for $\mathrm{G} 2$, with statistical significance $(p<0.02)$. The intergroup comparison verified a statistically significant reduction $(p<0.03)$, indicating that BMAC therapy was beneficial.

The quality of life within groups, assessed with by EuroQol 5D, showed statistically significant values in both groups. At six-month follow up, patients treated with BMAC presented an average increase of 0.16 $(p<0.002)$ in EuroQol 5D values, whereas patients treated with corticosteroids presented a $0.11(p<0.01)$ increase. We found no statistically significant difference when comparing both groups (Table 2).

Table 2. Intergroup and intragroup comparison of the Visual Analogue Scale and the EuroQol 5D and Lequesne questionnaires.

\begin{tabular}{c|c|c|c}
\hline Variables & $\begin{array}{c}\text { BMAC Group } \\
(\mathbf{n}=\mathbf{1 5})\end{array}$ & $\begin{array}{c}\text { Corticosteroid Group } \\
(\mathbf{n}=\mathbf{2 5})\end{array}$ & p-value* \\
\hline VAS & Median (IQR) & Median (IQR) & \\
\hline Baseline & $6.0(5.0-7.0)$ & $6.0(4.0-7.5)$ & 0.619 \\
\hline 1st month & $3.0(2.0-4.0)$ & $3.0(2.0-5.0)$ & 0.562 \\
\hline 6th month & $2.0(2.0-3.0)$ & $4.0(2.5-6.0)$ & 0.014 \\
\hline p-value** & 0.001 & 0.001 & \\
\hline EuroQol 5D & Average \pm SD & Average \pm SD & \\
\hline Baseline & $0.52 \pm 0.22$ & $0.50 \pm 0.33$ & 0.752 \\
\hline 6th month & $0.68 \pm 0.18$ & $0.61 \pm 0.25$ & 0.353 \\
\hline p-value ${ }^{* *}$ & 0.002 & 0.016 & \\
\hline Lequesne $^{*}$ & & & \\
\hline Baseline & $8.7 \pm 1.9$ & $8.0 \pm 3.6$ & 0.397 \\
\hline 6th month & $4.7 \pm 2.1$ & $6.8 \pm 3.3$ & 0.031 \\
\hline p-value* & $<0.001$ & 0.021 & \\
\hline
\end{tabular}

n: number of participants; IQR: interquartile range; SD: standard deviation; VAS: Visual Analogue Scale; **: Intergroup comparison (independent t-test or Mann-Whitney); *** Intragroup comparison (paired t-test or Wilcoxon).

When calculating the delta values of this study outcomes - obtained by subtracting baseline scores from the six-month follow up we found VAS scores to present a 3.5-point median reduction in the BMAC-treated group and a 1.6-point reduction in the corticosteroid-treated group, with statistical significance. Likewise, G1 presented a 4-point reduction in the Lequesne index, whereas G2 presented a 1.1-pointreduction. We found no statistically significant difference regarding EuroQol 5D values between groups, increasing quality of life by 0.16 in the BMAC group and by 0.12 in the corticosteroid group (Table 3). 
Table 3. Intergroup comparison of scores variability regarding the Visual Analogue Scale and the EuroQol 5D and Lequesne Index questionnaires.

\begin{tabular}{l|c|c|c}
\hline \multicolumn{1}{c|}{ Variables } & $\begin{array}{c}\text { BMAC Group } \\
(\mathbf{n}=\mathbf{1 5})\end{array}$ & $\begin{array}{c}\text { Corticosteroid Group } \\
(\mathbf{n}=\mathbf{2 5})\end{array}$ & $\mathbf{p}^{\text {-value }}$ \\
\hline$\Delta$ VAS & $-3.5 \pm 1.5$ & $-1.6 \pm 1.8$ & 0.001 \\
\hline$\Delta$ EuroQol 5D & $0.16 \pm 0.15$ & $0.12 \pm 0.23$ & 0.590 \\
\hline$\Delta$ Lequesne & $-4.0 \pm 2.0$ & $-1.1 \pm 2.3$ & $>0.001$ \\
\hline n: number of participants; VAS: Visual Analogue Scale; ** Intergroup comparison (Independentt-test).
\end{tabular}

\section{DISCUSSION}

Studies addressing tendinopathies are still scarce in the literature, so a limited number of patients is monitored regarding this condition. The first studies on the use of cell therapy in the treatment of tendinopathy were published in 2012. A group of researchers from a sports medicine center in New York published a series of eight cases of patellar tendinopathy treated with bone marrow mesenchymal stem cells. A study conducted in Brazil evaluated 14 individuals. Only case reports are found on the study of gluteal tendinopathy. Several preclinical studies were also developed in other mammalian and in vitro species in an attempt to clarify bone marrow aspirate concentrate (BMAC) mechanisms of action in tendinopathies. ${ }^{9-11}$

Studies employing corticosteroid injection in the treatment of tendinopathies present a higher proportion of women. In turn, those employing BMAC comprise an equivalent proportion between sexes, like ours. Studies using corticosteroids for gluteal tendinopathy found pain to be higher than 5 (according to VAS scale) in about $40 \%$ of patients three months after the procedure. ${ }^{4,12,13}$

The literature tends to agree that medication use, physical therapy, or surgical treatment have poor outcomes and few benefits to the patient when performed isolated. For patients with greater trochanteric pain syndrome (GTPS) to achieve a favorable well-being, they must undergo a multidisciplinary treatment involving changing lifestyle habits (regular physical activity, weight loss, muscle strengthening, and stretching), doing physical therapy, and controlling underlying pathologies and pain (GTPS)..$^{14,15}$

Among the different local adjuvant therapies used to treat GTPS, the most common is corticosteroid injection. Using ultrasound for corticosteroids injection in the trochanteric region achieved promising results to the treatment. Long-term studies corroborate the results found in our research: although treatment with corticosteroid injection present positive clinical results at one-month follow-up, a serial evaluation showed that from two to six months after the procedure pain level switch back to values similar to those recorded at baseline. That is, treatment with corticosteroids promote a short-term reduction in pain and inflammation. Corticosteroid injections also pose risks related to inhibition of collagen synthesis and induction of apoptosis, reducing tendon resistance and increasing the risk of rupture. ${ }^{16,17}$

BMACs are already being employed in experimental treatments of tendon disorders in different parts of the human body. Treatments for patellar tendinopathy, rotator cuff, and lateral epicondylitis with BMAC have presented positive clinical results. ${ }^{18,19}$

GTPS requires a multidisciplinary treatment rather than a specific therapy, entailing comorbidities control, changes in lifestyle habits, and physical therapy. ${ }^{11}$ When compared to the standard treatment that uses corticosteroid injection, BMAC showed promising outcomes as a local adjuvant therapy for GTPS.

\section{CONCLUSION}

Bone marrow aspirate concentrate (BMAC) represents a promising alternative to corticosteroids in the treatment of hip tendinopathy. When compared to conventional local therapy, BMAC reached statistically significant scores in the Visual Analogue Scale (VAS) for pain and Lequesne algofunctional index. The technique proved to be safe and feasible when administered along with a multimodal treatment involving different areas within health science.

AUTHORS' CONTRIBUTIONS: Each author contributed individually and significantly to the development of this article. DAVR: Writing of the article and performing surgeries; TBF: Writing of the article and performing surgeries; BAFMF: Writing of the article and interpreting data; GCD: Performing surgeries and final approval of the manuscript version to be published; RM: Data interpretation and final approval of the version of the manuscript to be published.

\section{REFERENCES}

1. Grimaldi A, Fearon A. Tendinopathy: Integrating Pathomechanics and Clinical Features in Its Management. J Orthop Sports Phys Ther. 2015;45(11):910-22.

2. Albers IS, Zwerver J, Diercks RL, Dekker JH, Akker-Scheek IVD. Incidence and prevalence of lower extremity tendinopathy in a Dutch general practice population: a cross sectional study. BMC musculoskelet disord. 2016;17:16

3. Barratt PA, Brookes N, Newson A. Conservative treatments for greater trochanteric pain syndrome: a systematic review. Br J Sports Med. 2017;51(2):97-104.

4. Brinks A, Rijn RMV, Willemsen SP, Bohnen AM, Verhaar JAN, Koes BW, et al Corticosteroid Injections for Greater Trochanteric Pain Syndrome: A Randomized Controlled Trial in Primary Care. Ann Fam Med. 2011;9(3):226-34.

5. Chong AKS, Ang AD, Goh JCH, Hui JHP, Lim AYT, Lee EH, et al. Bone Marrow-Derived Mesenchymal Stem Cells Influence Early Tendon-Healing in a Rabbit Achilles Tendon Model. J Bone Joint Surg Am. 2007;89(1):74-81.

6. Cohen SP, Strassels SA, Foster L, Marvel J, Williams K, Crooks M, et al. Comparison of fluoroscopically guided and blind corticosteroid injections for greater trochanteric pain syndrome: multicentre randomised controlled trial. BMC musculoskelet disord. 2009;338(14):1-7.

7. Daltro G, Franco BA, Faleiro TB, Rosário DAV, Daltro PB, Fortuna V. Osteonecrosis in sickle cell disease patients from Bahia, Brazil: a cross-sectional study. Int Orthop. 2018;42(7):1527-34.

8. Hernigou, P, Lachaniette CHF, Delambre J, Zilber S, Duffiet P, Chevallier N, et al. Biologic augmentation of rotator cuff repair with mesenchymal stem cells during arthroscopy improves healing and prevents further tears: a case-controlled study. Int Orthop. 2014;38(9):1811-8.

9. Pascual-Garrido C, Rolón A, Makino A. Treatment of Chronic Patellar Tendinopathy with Autologous Bone Marrow Stem Cells: A 5-Year-Followup. Stem Cells International. 2012;2012: 953510.
10. Gomes JLE, Silva RC, Silla LMR, Abreu MR, Pelland R. Conventional rotator cuff repair complemented by the aid of mononuclear autologous stem cells. Knee Surg Sports Traumatol Arthrosc. 2012;20(2):373-7.

11. Fearon AM, Cook JL, Scarvell JM, Neeman T, Cormick W, Smith PN. Greater Trochanteric Pain Syndrome Negatively Affects Work, Physical Activity and Quality of Life: A Case Control Study. Journal Arthroplasty. 2014;29(2):383-6.

12. Harris MT, Butler D, Boivin GP, Florer JB. Mesenchymal stem cells used for rabbit tendon repair can form ectopic bone and express alkaline phosphatase activity in constructs. Orthopaedic Research Society. 2004;22(5):998-1003.

13. Henderson RG, Colberg RE. Pure bone marrow aspirate injection for chronic greater trochanteric pain syndrome: a case report. Pain Manag. 2018;8(4):271-5.

14. Lequesne M, Mathieu P, Vuillemin-Bodaghi V, Bard H, Djian P. Gluteal tendinopathy in refractory greater trochanter pain syndrome: Diagnostic value of two clinical tests. Arthritis Rheum. 2008;59(2):241-6.

15. Mellor R, Bennell K, Barry R, Grimaldi A, Nicolson P, Kasza J, et al. Education plus exercise versus corticosteroid injection use versus a wait and see approach on global outcome and pain from gluteal tendinopathy: prospective, single blinded, randomised clinical trial. BMC Musculoskelet Disord. 2018;12(361):1-9.

16. Del Buono A, Papalia R, Khanduja V, Denaro V, Maffulli N. Management of the greater trochanteric pain syndrome: a systematic review. Br Med Bull. 2012;102(1):115-31.

17. Rasmussen KJE; Fanø N. Trochanteric Bursitis: Treatment by Corticosteroid Injection. Scand. J. Rheumatol. 1985;14(4):417-20.

18. Segal NA, Felson DT, Torner JC, Zhu Y, Curtis JR, Niu J, et al. Greater Trochanteric Pain Syndrome: Epidemiology and Associated Factors. Arch Phys Med Rehabil. 2007;88(8):988-92.

19. Singh A, Gangwar DS, Singh S. Bone marrow injection: A novel treatment for tennis elbow. J Nat Sci Biol Med. 2014;5(2):389-91. 